\title{
O lugar da ficção na produção textual da Etnomatemática
}

\author{
Fabio Lennon Marchon'1(i) \\ Universidade Federal Fluminense (UFF), Faculdade de Educação, \\ Departamento Sociedade Educação e Conhecimento, Niterói, Rio De Janeiro, Brasil.
}

\begin{abstract}
Resumo
Este trabalho evidencia alguns dos aspectos da narrativa inscrita no mundo do texto de Ubiratan D'Ambrosio e, em particular, aquela presente em suas obras destinadas a divulgação da Etnomatemática. Destacam-se as intersecções literárias efetuadas no plano do texto e o campo de possibilidades abertas pela ficcionalização das histórias em sua escrita. A perspectiva teórica e metodológica se inspira na hermenêutica narratológica ricoeuriana e adota a composição da intriga como fio condutor da análise/interpretação.
\end{abstract}

Palavras-chave: Narrativa; Ficção; Etnomatemática; Composição da Intriga.

\section{The place of fiction in textual production of Ethnomatematics}

\begin{abstract}
This work highlights some of the aspects of the narrative inscribed in the world of Ubiratan D'Ambrosio's text and, in particular, that present in his works aimed at disseminating Ethnomathematics. The literary intersections made in the text and the field of possibilities opened by the fictionalization of stories in its writing stand out. The theoretical and methodological perspective is inspired by the Ricoeurian narratological hermeneutics and adopts the composition of the plot as the guiding thread of the analysis/interpretation.
\end{abstract}

Keywords: Narrative. Fiction. Ethnomathematics. Composition of the intrigue.

\section{El lugar de la ficción em la producción textual de Etnomatemática}

\section{Resumen}

En esta obra se destacan algunos de los aspectos de la narrativa inscritos en el mundo del texto de Ubiratan D'Ambrosio y, en particular, el presente en sus obras destinadas a difundir la Etnomatemática. Destacan las intersecciones literarias realizadas en el texto y el campo de posibilidades que abre la ficcionalización de los relatos en su escritura. La perspectiva teórica y metodológica se inspira en la hermenéutica narratológica ricoeuriana y adopta la composición de la trama como hilo conductor del análisis / interpretación.

Palabras clave: Narrativa. Ficción. Etnomatemáticas. Composición de La intriga.

Submetido em: 26/06/2021 Aceito em: 18/08/2021 Publicado em: 03/09/2021 ${ }^{1}$ Doutor em Educação pela Universidade Federal Fluminense. Professor do curso de Pedagogia da Universidade Federal
Fluminense. E-mail: fabiolennon@id.uff.br. 


\section{Introdução}

Este artigo é fruto de uma pesquisa maior feita em nível de doutoramento que, naquele momento, se dedicou à poética e a retórica do texto etnomatemático de D'Ambrosio. Faz-se, agora, um recorte para explicitar alguns elementos que participam desta escrita.

O objeto analisado/interpretado neste trabalho é o chamado mundo do texto (RICOEUR $2012 \mathrm{a} ; 2012 \mathrm{~b} ; 2012 \mathrm{c}$ ) - “O que é, com efeito, interpretado em um texto é um mundo pró-posto (proposé), um mundo que eu poderia habitar e no qual eu poderia projetar minhas capacidades mais próprias" (RICOEUR, 2012, p.300) - e, mais precisamente, o mundo do texto etnomatemático de D'Ambrosio (1985, 1986, 1990, 2011). Os pensamentos textualizados, as ideias enunciadas, as crenças proferidas, os valores defendidos e, também, e não menos significativos, os conhecimentos enredados na trama textual de D'Ambrosio fazem parte deste mundo.

Observa-se que D’Ambrosio foi um dos principais personagens envolvidos na construção teórica da Etnomatemática e, também, um dos maiores defensores e divulgadores do ideal etnomatemático no campo da Educação Matemática no Brasil, reconhecido por alguns pesquisadores como o pai da Etnomatemática (MIARKA, 2011; GERDES, 1996, 2010; KNIJNIK, 2004, 2012; FANTINATO \& FREITAS, 2018; CONRADO, 2005; ROSA \& OREY, 2014). Além disso, nota-se que D’Ambrosio permanece como uma das principais referências teóricas em outros estudos e pesquisas (FANTINATO \& FREITAS, 2018). Assume-se, dentro destes limites, que o universo textual d'ambrosiano influencia o pensamento e a escrita de outros sujeitos no campo da pesquisa (BAMPI, 2003; BREDA, 2011), o que evidencia a relevância desta investigação.

A analítica e a interpretação realizadas nesta empreitada inspiram-se nos trabalhos do filósofo francês Paul Ricoeur (1913-2005). Explora-se a composição das intrigas (RICOEUR, 2012a, 2012b, 2012c) que entretecem as narrativas das histórias contadas por D’Ambrosio em seu mundo do texto etnomatemático. Busca-se, com isso, evidenciar o lugar da ficção em seus escritos. As reflexões do historiador Hayden White (1928-2018) podem ser acionadas neste cenário, pois, de acordo com o historiador:

O modo como uma determinada situação histórica deve ser configurada depende da sutileza com que o historiador harmoniza a estrutura específica de enredo com o conjunto de acontecimentos históricos aos quais deseja conferir um sentido particular. Trata-se essencialmente de uma operação literária, vale dizer, criadora de ficção. (WHITE, 2014, p. 102).

Poder-se-ia indagar, neste contexto, "Qual o papel da literatura ficcional na composição do enredo da narrativa d'ambrosiana?", ou, ainda, “como e quando a escrita ficcional é acionada no 
interior da obra textual assinada pelo referido educador matemático?” ou, de modo mais abrangente, “qual o lugar da ficção na produção textual da Etnomatemática?”.

\section{O texto, a composição da Intriga e a ficção}

A intriga (trama, enredo) de uma narrativa é uma das principais categorias de análise e interpretação propostas por Ricoeur (2012a, 2012b, 2012c) e, mais precisamente, a composição da intriga $^{2}$, ou seja, os modos como se entretece a trama da narrativa dentro do mundo do texto. De acordo com o filósofo, na composição da intriga - mythos ${ }^{3}$ - imita-se a ação do homem e, na narrativa, essa ação passa por transformações, do início ao fim da história, com objetivo de sensibilizar e emocionar o leitor (RICOEUR, 2012a). O hermeneuta francês afirma, além disso, que "a composição da intriga constitui um autêntico componente da operação historiográfica" (RICOEUR, 2007, p.250), pois, a saber, "a intriga é a forma literária dessa coordenação: ela consiste em conduzir uma ação complexa de uma situação inicial para uma situação terminal por meio de transformações regradas" (RICOEUR, 2007, p.255).

Outras categorias de análise podem ser acionadas na investigação, como, por exemplo, os personagens e suas funções na trama, o tempo da narrativa, o espaço-ambiente em que as ações ocorrem e, ainda, o narrador e a voz da narrativa. Assim, por exemplo, sobre o narrador e o escritor, estabelece-se a seguinte distinção:

O escritor é um ser humano que existiu ou existe, em carne e osso, no nosso universo. Sua existência se situa no "não-texto". Ao seu lado, o narrador - aparente ou não só existe no texto e mediante o texto, por intermédio de suas palavras. De qualquer modo ele é um enunciador interno: aquele que, no texto, conta a história. (REUTER, 2014, p.19).

Uma observação pertinente neste ponto diz respeito ao texto. Para o filósofo francês a noção de texto relaciona-se com o conceito de discurso, a inscrição do discurso e, além disso, o texto estabelece um espaço de distanciamento (RICOEUR, 2011) entre o mundo do texto e o mundo empírico, sócio-histórico - “o fato de ser escrito faz do discurso o portador de uma história que já não é a de seu autor" (RICOEUR, 2011, p. 29).

As narrativas que emergem dos rastros das memórias do escritor e que se materializam na trama a partir da voz do narrador, apesar de assumirem as vestes históricas da historiografia, ou seja,

\footnotetext{
${ }^{2}$ Lê-se em Carneiro (2013) que este caminho metodológico entrelaça hermenêutica e narratologia pelo fio da intriga.

${ }^{3} \mathrm{O}$ termo grego no texto aristotélico é mythos que, em sua tradução, aceita os dois significados explicitados: fábula ou intriga. (RICOEUR, 2012a).
} 
de assumirem intenções de verdade, são ainda, histórias. E, nesse contexto, podem ser entendidas, como ficções verbais (RICOEUR, 2012a) em um mundo possível (o mundo do texto).

O exercício que se propõe nesta jornada analítica e interpretativa é a de que o mundo do texto etnomatemático de D’Ambrosio seja encarado como um objeto literário. O ficcional da obra neste movimento se revelará para o leitor. O sentido da palavra ficção está atrelado, neste caso, à "história e o mundo construído pelo texto e existente apenas por suas palavras, suas frases, sua organização etc.” (REUTER, 2014, p.17).

\section{O lugar da literatura na vida do escritor}

Qual o papel e o valor da literatura para Ubiratan D'Ambrosio? Em uma entrevista, no ano de 2008, o educador matemático fornece algumas pistas sobre o papel que a literatura desempenha em sua formação, em seu modo de ver e entender o mundo e, também, em sua própria escrita ${ }^{4}$. Segundo ele, na adolescência, cresceu o seu interesse pelas leituras históricas e também pela literatura de ficção - Shakespeare (em inglês), Cervantes (em espanhol), Balzac e Flaubert (em francês). Ele nos revela que:

Não aprendi alemão — lamento - e não conheci Goethe, Thomas Mann e tantos outros escritores alemães, que eu só iria encontrar um pouco mais tarde, em traduções. Esses autores muito me marcaram. Num momento da vida, aproximandome dos quarenta anos, descobri uma outra direção de leitura, uma maior intimidade com o autor e a busca de algo que ele não quis tornar explícito. Foi uma busca de uma dimensão mística, talvez psíquica, da espiritualidade intrínseca à obra. Situo o ponto de partida para o redirecionamento de minhas leituras meu acesso ao livro de Rollo May: Love and Will. Aprendi a ler o meu íntimo (D’AMBROSIO, 2008, p.20).

Segundo ele, "Daí foi uma re-fascinação pela História e pela releitura dos clássicos gregos" (D’AMBROSIO, 2008, p.20), e, além disso, também “Freud, Jung e William Reich [...] Thomas Mann, Aldous Huxley, Hermann Hesse e o impressionante Robert Musil” (D’AMBROSIO, 2008, p.20). O matemático prossegue:

Também fui muito influenciado pelo pensamento crítico francês do pós-guerra. Particularmente Lacan, Derrida, Sartre, Merleau-Ponty, Foucault e daí por diante. Foi uma forma de me descobrir. O cinema alemão, particularmente Fassbinder e Herzog, como já havia acontecido com Bergman, se encaixaram muito bem no meu crescente interesse pela visão transdisciplinar e transcultural do mundo simbólico. As leituras populares sobre esse mundo simbólico, então best-sellers entre os mais jovens, me atraíram muito. Li, com muito interesse, o J.D. Salinger, e o interessantíssimo Zen e a Arte de Manutenção de Motocicletas, de Pirsig. Essa aproximação com o Oriente, característica do início da segunda metade do século XX, foi e continua sendo, para mim, muito atrativa. (D’AMBROSIO, 2008, p.20)

${ }^{4}$ Fonte: Revista Rascunho, ano 9, número 102, outubro de 2008. 
Neste ponto poder-se-ia assumir que a produção textual d'ambrosiana possui uma dimensão literária/ficcional implícita e que, uma hipótese a ser explorada, é a da intertextualidade e da multiplicidade de vozes que ecoam em seu mundo do texto. D'Ambrosio acrescenta, em sua entrevista, que:

$\mathrm{Na}$ verdade, eu sentia que a questão social, por exemplo como presente no cinema neorealista, deve necessariamente passar pela questão do indivíduo, na sua intimidade. Passei a ver no equilíbrio intimidade-alteridade o significado de felicidade na condição humana. Nesse momento, eu estava muito envolvido com questões de paz, sendo ativo no Movimento Pugwash, do qual fui membro do Conselho (órgão maior do Movimento). O movimento ter recebido Prêmio Nobel da Paz foi um grande estímulo para uma releitura mais cuidadosa dos clássicos, principalmente A Arte da Guerra, de Sun Tzu, O Príncipe, de Maquiavel, Da Guerra, de Von Clausewitz e, naturalmente, Guerra e Paz. Também Shakespeare ajudou muito ao entender o (des)equilíbrio entre emocional e poder, outra forma de intimidade versus (ou mais?) alteridade. (D'AMBROSIO, 2008, p.20)

O matemático, então, assume algo que, até aqui, apenas se insinuou, a saber, que "A literatura de ficção científica, com cenários de um futuro imaginoso e fantasioso, tem me atraído e se incorporou aos meus cursos e palestras" (D'AMBROSIO, 2008). O futuro possível, distinto do momento presente enunciado, parece ser especialmente importante na composição das narrativas das histórias que povoam o mundo do texto etnomatemático d'ambrosiano. E, por fim, ele atesta o seguinte:

Literatura é parte integrante de meu dia. Mantenho excelente diálogo com os autores e discuto muito com críticos literários. Gosto muito de crítica literária. Meu método de trabalho aponta para o encontro com o diferente. Hoje, desde já há alguns anos, minha atividade é, fundamentalmente, a história da humanidade, focalizando principalmente a história das religiões, a história da ciência e a história da matemática. (D’AMBROSIO, 2008, p.20)

Pode-se afirmar que nesse momento de redescoberta da literatura, de encontro com o cinema, de debate com a crítica literária, em que o matemático realiza suas releituras dos clássicos gregos, ele também começa a produzir o seu texto etnomatemático. Há, portanto, no plano sócio-histórico da experiência concreta do escritor um enorme repertório literário/ficcional que possivelmente se materializa em sua produção escrita.

\section{Da enunciação ao enunciado}

Observa-se que uma parte significativa da produção textual do educador matemático está assentada sobre uma textualização do seu discurso oral (D’AMBROSIO, 1985, 1986, 1990). Muitas das suas reflexões emergem de entrevistas, debates e palestras (MARCHON, 2018). Parte da sua produção percorre o caminho que vai da enunciação ao enunciado, da oralidade à 
textualidade/escritura. Sendo assim, entende-se que parte da obra textual que chega até o leitor foi inicialmente idealizado para a apresentação diante de uma plateia ${ }^{5}$. Há de se considerar para fins interpretativos, portanto, os distanciamentos existentes entre o que foi dito, falado, pronunciado pelo sujeito sócio-histórico, empírico, de carne e osso, em certo espaço-tempo, com sua intencionalidade específica, para um determinado público, e o que foi posteriormente transcrito e textualizado para um leitor potencial qualquer e narrado pela voz de um narrador.

Entende-se, portanto, que um dos objetivos não enunciados pelo matemático e que deve ser assumido como relevante na analítica é sua intenção de convencer e persuadir o publico ouvinte em cenários e contextos específicos. Comunicar suas ideias educacionais acerca do ensino da matemática para um auditório real, resistente às suas ideias, é algo que deve ser considerado pelos leitores do mundo do texto etnomatemático d'ambrosiano. O desafio do educador matemático não era propriamente, e tão somente, o de informar algo a alguém, mas sim, fundamentalmente, o de conquistar a simpatia e adesão de um público hostil às ideias enunciadas (ver, por exemplo, o prefácio em D’AMBROSIO, 1986).

\section{Personagens}

Uma primeira observação acerca do texto produzido e assinado por D'Ambrosio é a proliferação de personagens e a multiplicidade de vozes que ecoam em seu mundo do texto. Alguns são sujeitos reais, socio-históricos, outros puramente ficcionais, produtos da criação literária. Neste encontro da realidade com a fantasia o escritor entretece fatos e ficções para produzir seus argumentos de convencimento e persuasão.

tanto "Lumsden" quanto "Wilson" surgem na história como personagens secundários identificados por seus nomes; são seres não-fictícios e possuidores de uma identidade; a eles se associa alguma ideia, conceito ou pesquisa que, no interior da história narrada por D'Ambrosio (1985) assume alguma importância. Analogamente, quando o narrador-autor atesta que "ideology, implicit in dressing, housing, titles, so superbly demounced by Aimée Cesaire in La Tragédie du Roi

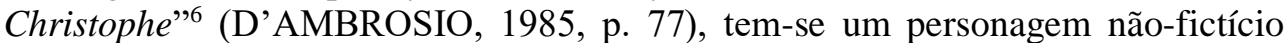
(Aimée Cesaire) e um personagem fictício (Rei Christophe) que surgem na composição do enredo para fundamentar as reflexões acerca da ideologia. (MARCHON, 2018, p. 180)

\footnotetext{
${ }^{5}$ Entenda-se aqui, neste contexto, que muitas das ideias defendidas por D'Ambrosio foram apresentadas em seminários, palestras, mesas redondas, etc. Assim, pessoas de carne e osso, sujeitos socio-históricos, alguns simpatizantes e outros críticos das ideias proferidas, estavam presentes na plateia.

${ }^{6}$ Tradução nossa: "Ideologia, implícita em vestimentas, moradia, títulos, tão devidamente denunciadas por Aimée Cesaire em La Tragédie du Roi Christophe".
} 
Ao compor sua intriga D’Ambrosio explora, ainda, o aspecto dramático (no sentido teatral), encenando falas e acontecimentos para uma plateia virtual. Assim, por exemplo, ao se apropriar da voz do personagem Dom Quixote, simula um diálogo fictício com o seu leitor — "Forgive me, my friend, for having caused you to appear as mad as I by leading you to fall into the same error, that of believing that there are still knight-errant in the world"' (D'AMBROSIO, 1985, 1986, 1999) [Tradução nossa: "Perdoe-me, meu amigo, por ser a causado de você parecer tão louco quanto eu, levando você a cair no mesmo erro, em acreditar que ainda há cavaleiros errantes no mundo" ]. O escritor se apropria da voz do cavaleiro errante que, ao fim de sua jornada, em seu leito de morte, pede desculpas ao seu leal escudeiro. Alguns personagens observados em D’Ambrosio (1985) pode ser visto abaixo:

Tabela 1 - personagens em D’Ambrosio(1985).

\begin{tabular}{|c|c|}
\hline \multicolumn{2}{|c|}{ Personagens } \\
\hline Personagens nomeadas & Personagens tipo-genéricos \\
\hline $\begin{array}{l}\text { Ubiratan D’Ambrosio; C.G. Jung; Meister Eckart; } \\
\text { A. Koestler; Charles Morazé; César Lombroso; P. } \\
\text { Picasso; Bernard Shaw; Leonard B. Mayer; } \\
\text { François Jacob; Dom Quixote; Miguel de } \\
\text { Cervantes; Isaac Newton; David Baltimore; } \\
\text { Keukulé; Hadamard; Poincaré; Paul Feyerabend; } \\
\text { Alfred Sohn-Rethel; Kwasi Wiredu; Michel } \\
\text { Foucault; R. L. Wilder; Lumsden e Wilson; } \\
\text { Smorynski; Tadasu Kawaguchi; Robert Musil; } \\
\text { Törless; Gaston Bachelard; Jürgen Habermas; } \\
\text { J.L. Austin e A.G. Howson; H. Burkardt; B. } \\
\text { Spotorno e V. Villani; Eduardo Luna; Bryan } \\
\text { Wilson; Aimée Cesaire; Rei Christophe; George } \\
\text { Cantor; K. Marx; C. Darwin; L. Kroenecker; } \\
\text { Manzoor Ahmed; Merian Wbster; Philip J. Davis } \\
\text { e Reuben Hersh; Mircea Malitza; Touré; } \\
\text { Chamorro; Patrick J. Scott; Gloria Gilmer. }\end{array}$ & $\begin{array}{l}\text { ISGEm; Western Thought; The Creator; Book of } \\
\text { genesis; People ; We/ us; Students; Learners; } \\
\text { society; Mathematics; Ethnomathematics; } \\
\text { Curricula; Tradional way; School system; } \\
\text { School mathematics; Mathematics education; } \\
\text { Secondary school teachers of mathematics; } \\
\text { Secondary school systems; Teachers; } \\
\text { Unqualified teachers; Children; Industrialized } \\
\text { countries; Developing countries; Latin American } \\
\text { Countries; Lower middle class; Uneducated } \\
\text { people; Illiterates; Our species }\end{array}$ \\
\hline
\end{tabular}

Fonte: Marchon (2018)

\footnotetext{
${ }^{7}$ Epígrafe do último capítulo de D’Ambrosio (1985). A fala em destaque faz parte da obra de Cervantes, "the death of Don Quixote". Esta mesma citação está no prefácio de D’Ambrosio (1986) e em outras produções do educador matemático.
} 
Os personagens tipos-genéricos que preenchem a narrativa não são detalhados, desenvolvidos ou tem um perfil aprofundado na trama. Estes, em geral, representam uma coletividade, um grupo, uma massa indistinta de seres. Implicitamente assume-se uma ideia de identidade coletiva. Planificação que cria uma ideia de homogeneidade dos seres que compõem o grupo. Assim, por exemplo, fala-se: os gregos, o homem ocidental, países do terceiro mundo, nossa espécie, pessoas iletradas, pobres da classe média, professores, pensamento ocidental, etc

\section{A ficção utópica}

Pode-se dizer que, em muitos sentidos, o texto etnomatemático d'ambrosiano se desloca entre a narrativa histórica e a narrativa utópica, do gênero historiográfico ao gênero literário utópico (TROUSSON, 2005; SARGENT, 2005; FIRPO, 2005; CIORAN, 1994), dos fatos à ficção. Para melhor compreender esse deslocamento, cabe reconhecer alguns dos elementos característicos das narrativas utópicas. A escrita histórica de D’Ambrosio descreve um mundo em ruínas, ameaçador, problemático. É necessário apresentar poeticamente aquilo que exige de nós, sujeitos socio-históricos, comprometimento para a mudança. Somente a partir daí é possível enunciar um novo modelo de mundo.

There would be no need to emphasize that society going through dramatic changes in the last 30 years. Coming from the destruction seen in World War II, which more than anything else agravated the tensions and contradictions resulting in part from the internal crisis of the capitalistic mode of production and property, and on the other part from the almost dichotomic unbalance on economics, social and political development between the so-called North and South nations. In the other terms, by the shameful misery which characterizes Third World nations in contrast with ever increasing prosperity in the developed countries. ${ }^{8}$ (D'AMBROSIO, 1985, p.8-9)

A escrita etnomatemática d'ambrosiana descreve um passado temeroso e sugere um deslocamento ético do homem rumo a um futuro melhor. Ele cria o ideal de um mundo ainda por vir. Pode-se dizer que uma das proposições da Etnomatemática d'ambrosiana, em suas primeiras elaborações (D’Ambrosio, 1985, 1986, 1990), é a da superação da terrível realidade apresentada para o leitor. Este trabalho não pretende avançar sobre uma analítica do aspecto literário utópico da escrita

\footnotetext{
${ }^{8}$ Tradução nossa: "Não seria necessário enfatizar que a sociedade atravessa mudanças dramáticas nos últimos 30 anos. A partir da destruição vista na Segunda Guerra Mundial, que mais do que qualquer outra coisa agravou as tensões e as contradições resultantes em parte da crise interna do modo capitalista de produção e propriedade e, por outro, do desequilíbrio quase dicotômico sobre economia, social e desenvolvimento político entre os chamados países do Norte e do Sul. Nos outros termos, pela miséria vergonhosa que caracteriza as nações do Terceiro Mundo em contraste com a prosperidade cada vez maior nos países desenvolvidos" (D'AMBROSIO, 1985, p.8-9).
} 
d'ambrosiana, mas, no entanto, indica-se como caminho as categorias elencadas por Marques (2009) em sua poética da perfeição 9 .

\section{Crise e apocalips}

O texto etnomatemático de D’Ambrosio também recorre, no nível da composição da intriga, a uma poética apocalíptica (KERMODE, 2000). A crise instituída pelo pensamento apocalíptico permite que a narrativa se estruture a partir de uma sequência de ações, até o momento que antecede o fim emblemático, de modo que seja possível reverter a crise enunciada. A narrativa deve sofrer, portanto, uma reviravolta emblemática na ação.

O tempo da história narrada depende do final mítico descrito e da crise que a antecede e, por isso, inevitavelmente, a história afirma que o tempo presente é o tempo da transição, da transformação, é o tempo de um estar entre. D’Ambrosio (1990) cria uma história que narra um momento crítico, perturbador e angustiante para a espécie humana. Todos os homens se encontram, em sua história (story) da História (history), à beira da extinção.

Estaremos atingindo o final de um modelo cognitivo em que ao mesmo tempo em que nos permite nos aproximarmos de uma verdade totalizadora, que nos desvenda o pequeno e o grande, o interior e o exterior, nos força a dar o passo final em direção ao sacrifício total, e assim atingirmos a meta existencial, estendendo para toda a espécie a meta da extinção em direção à qual inexoravelmente caminhamos como indivíduos? (D’AMBROSIO, 1990, p. 44)

A mudança é necessária para que a trama tenha um desfecho não apocalíptico. Busca-se enlaçar o leitor, comprometê-lo eticamente, para evitar o "sacrifício total" (idem) anunciado. Como evitar o fim apocalíptico? O que poderá solucionar a crise enunciada? Dentro da argumentação d'ambrosiana a matemática e o seu ensino estão na base de todas as transformações tecnológicas e científicas que pode, para o bem ou para o mal, mudar a humanidade. E, assim sendo, uma solução

\footnotetext{
9 (1) a construção de um mundo ideal como alternativa ao real; (2) a crença na espécie humana; o homem como redentor do homem (antropocentrismo); (3) a defesa de um código legislativo/ético capaz de promover o bem-estar público em que o "dever-ser" se converte em "ser"; (4) o mundo utópico é regido pelo princípio da utilidade; todas as engrenagens sociais devem ser funcionais e úteis; (5) cria-se uma uniformidade social; a convergência de interesses visa apaziguar os conflitos humanos; (6) o mundo utópico é unidirecional e constrange a todos a seguir um modelo em que o "mal não toca" (CIORAN, 1994, p.103); (7) a narrativa utópica promove o sonho da felicidade coletiva e "o utopista aconselha, de boa vontade, o coletivismo (TROUSSON, 2004, p. 36); (8) o herói individual cede lugar para o herói coletivo; (9) na utopia o mal não pode existir senão como o antagonista a ser superado; (10) a narrativa utópica só se estabelece a partir da presença de narradores-testemunhas, quase exterioridades do mundo descrito e, por isso mesmo, aptos a propor as transformações; (11) promove, ainda, uma viagem do real ao ideal, do abandono de antigos valores à proposição de novos; (12) a utopia se dirige para o futuro; (13) o espaço arquitetônico da utopia é o da matemática, da geometria, da ordenação do mundo; etc.
} 
proposta pelo matemático é agir no campo educacional, buscando a transformação da sociedade, a partir de um novo modelo de Educação Matemática.

“A Etnomatemática surge, nesse caso, como uma solução poética para a crise instituída na história" (MARCHON, 2018, p. 149). E, nesse contexto, lê-se o seguinte: "minha proposta educacional representa esperança de redenção para alguns e ameaça para outros" (D'AMBROSIO, 1985, p. 8).

\section{O jovem Törless na Etnomatemática}

Veja-se, por exemplo, retornando especificamente ao recorte do uso de personagens ficcionais na composição da intriga da narrativa, o caso do Jovem Törless (D’AMBROSIO, 1985). No terceiro capítulo do livro "Sociocultural bases of Mathematics Education", entre as páginas 51 e 56, o escritor se apropria de um fragmento ficcional para compor sua própria argumentação. Há, neste ponto da trama, um entrecruzamento dos aspectos dramático, poético e retóricos.

O escritor recorre à obra do escritor austríaco Robert Musil (1880-1942). Observa-se que, apesar da relevância do fragmento para a argumentação do escritor em seu texto, a obra não é mencionada em suas referências. Segundo o educador matemático, trata-se de uma das obras primas da literatura daquele século, escrito por um dos mais importantes escritoires de lingua germânica ${ }^{10}$. E, com isso, ele utiliza um argumento de autoridade com intuito de persuadir e convencer o ouvinte/leitor acerca do valor e da importância do material que será utilizado. A partir de um pacto implícito de confiança entre escritor e leitor, lê-se que:

É um estudo da adolescência através dos olhos de um aluno de dezesseis anos em uma academia militar seletiva. Entre as várias experiências do jovem Törless, há alguns questionamentos sobre números imaginários com seu colega Beineberg e uma entrevista subsequiente com seu professor de matemática. Os diálogos citados refletem uma visão externa do que é a matemática e a forma como a matemática é praticada na escola, exatamente na faixa etária que nos preocupamos neste artigo. A opinião de pessoas fora do círculo de praticantes de matemática - e aqui coloco tanto matemáticos quanto professores - expressam sobre a disciplina, como por exemplo, as de Robert Musil através dos personagens de seu trabalho, refletem de forma muito clara a nossa imagem aos olhos do público em geral e, consequentemente, dos nossos "clientes", os alunos. De fato, no sistema escolar tentamos vender uma idéia, transmitir uma mensagem. As pré-concepções que o aluno tem são determinantes, em grande medida, no sucesso ou na falha de nossa missão (D’AMBROSIO, 1985, p.51) Tradução própria

\footnotetext{
10 "In the 1906 the Austrian Robert Musil, one of the most important writers of the German language, published one of the the masterpieces of the literature of this century" (D’AMBROSIO, 1985, p. 51). Tradução nossa: "Em 1906 o austríaco Robert Musil, um dos mais importantes escritores de língua germânica (alemã), publicou uma das obras-primas da literatura deste século".
} 
A hipótese que se faz é a de que a visão do escritor Robert Musil acerca da matemática e do seu ensino, uma visão externa à matemática e distinta daquela compartilhada por matemáticos e professores de matemática, é totalmente repassada para a ação encenada pelos personagens do mundo ficcional. A ficção supostamente, neste caso, retrata a realidade como ela é de fato. A argumentação de D’Ambrosio (1985) vai do particular (o personagem Törless) ao geral (todos os estudantes adolescentes), do ficcional (a obra de Musil) ao real (o mundo empírico, socio-histórico, da década de 1980).

Uma observação, neste ponto, diz respeito ao jogo de perguntas e respostas ${ }^{11}$ que ocorre a partir da interação dialógica e de interlocução entre os personagens da obra fictícia:

During the mathematics period Törless was suddenly struck by an idea....

Törless - 'I say, did you really, understand all that stuff?'

Beineberg - 'What stuff?'

Törless - 'All that imaginary numbers.'

Beineberg -'Yes. It's not particularly difficult, is it? All you have to do is remember that the square root of minus one is the basic unit you work with.'

Törless - 'But that's just it. I mean, there's no such thing. The square of every number, whether it's positive or negative, produces a positive quantity. So there can not be any real number that could be square root of a minus quantity.'

And the dialogue between the two collegues proceed up to a breakdown. (D’AMBROSIO, 1985, p.52-53)

Observa-se que os diálogos encontram-se fora do seu contexto original. Tornam-se, neste sentido, novos diálogos. Eles estão em um contexto diverso da história ficcional de origem (MUSIL, 2003). E, neste caso, pode-se dizer que o diálogo ficcional simula um jogo entre o escritor e seu leitor potencial mediado pelas personagens. É, portanto, a leitura e interpretação que D’Ambrosio faz da obra de Musil que orienta a significação que o leitor poderá extrair do interior deste jogo de perguntas e respostas.

\footnotetext{
${ }^{11}$ Sobre isso importa recorrer às reflexões ricoeurianas. O filósofo francês afirma que "É em resposta a perguntas do tipo: que fazes, porquê, como e com que intenção?, que se produzem os enunciados da forma <<faço isto porque, em vista de, etc. > A forma do enunciado é assim selecionada pelo jogo das questões e das respostas e pela situação deste jogo no interior de um jogo mais vasto que é o da própria interação pela qual a ação de um responde à ação do outro.” (RICOEUR, 2013, p.45). É importante observar algumas distinções estabelecidas por Ricoeur (2013): "distinguir o universo do discurso em que se fala da ação do universo do discurso em que se fala do movimento. É ao primeiro que pertence a noção de motivo, ao segundo a noção de causa" (RICOEUR, 2013, p. 45); Ricoeur(2013) fornece dois exemplos que podem ajudar a esclarecer esta distinção: "Dizer $<<$ estico o braço para mostrar que vou virar $>>$ é produzir um enunciado que não pode situar-se na mesma categoria que o enunciado <<o braço levanta-se >> : este descreve um movimento, aquele uma ação; este descreve um movimento que é observado por um espectador, o segundo descreve uma ação do ponto de vista do agente que a fez" (idem). Ubiratan D'Ambrosio seria um observador externo a toda a ação da história? O escritorautor brasileiro se propõe a comentar os motivos que levam os personagens a certas as ações em sua estória da história; e ele o faz com base nas suas falas e, apenas com base nos enunciados, extrai os motivos que levam os personagens a dizer que agem como agem e pensam como pensam. Com base no diálogo da história o escritor-autor infere uma realidade extra-textual (sociohistórica) a partir da realidade fictícia do mundo do texto de Musil.
} 
O escritor, ao compor sua intriga, apegando-se aos fragmentos ficcionais de outro mundo, realiza certas escolhas, seleciona e organiza o material do qual se apropria. Ele age como na edição ${ }^{12}$ de um filme, realizando cortes, montagens, remodelando o contexto original da cena. D'Ambrosio (1985) interfere no original acrescentando seus comentários ou, ainda, removendo trechos inteiros. As lacunas, os hiatos, os intervalos — “[...]" — inscritos no texto do educador matemático não fazem parte da obra de Robert Musil e denunciam a montagem realizada sobre o original.

A montagem da cena na narrativa de D’Ambrosio (1985) efetua, também, uma desconstrução do contexto sociocultural, ideológico e político do original em que a história do jovem Törless ocorre. Descontextualizar e recontextualizar para compor a intriga da narrativa. A montagem e a edição da cena ficcional em D’Ambrosio (1985) desconsidera o mundo próprio em que a trama original se desenrola ${ }^{13}$.

A narrativa do educador matemático, a partir do fragmento ficcional, cria uma versão romanceada acerca do compartilhamento de experiências entre jovens e adolescentes no mundo socio-histórico, empírico, real ao atestar "the obvious identification of youth all over the world with their pairs"14 (D’AMBROSIO, 1985, p. 55). Na ficção sobre o ficcional projeta-se algo do real que, talvez, não se possa efetivamente comprovar no campo sociológico, psicológico ou histórico.

\section{Considerações finais}

A obra assinada pelo educador matemático abriu um novo caminho dentro da Educação Matemática ao dialogar com a literatura ficcional, as produções cinematográficas, as novas mídias digitais, e todo um amplo universo simbólico que ultrapassa o da educação matemática. Pode-se mesmo afirmar que os escritos de D’Ambrosio traçaram uma linha de fuga no mapa até então existente na Educação Matemática. Seu trabalho estabeleceu uma rota alternativa aos exploradores, pesquisadores, estudantes.

Ao criar uma realidade sobre a irrealidade da ficção, ao narrar uma história por vir e enunciar uma crise, um momento de transição, e apontar para o provável fim apocalíptico do ser humano, o escritor subverte e amplifica os fatos da realidade socio-histórica para, em sua argumentação,

\footnotetext{
12 “Aqui começa a se desconstruir também a noção de realidade, porque o corte dentro da cena mostra o mesmo fato de outra perspectiva, exige uma nova visão, a 'montagem intelectual' que Eisenstein vai teorizar em seus trabalhos logo nos anos 20. E com a montagem entrando em cena, como o nome indica, há o rearranjo dos fatos vistos pela câmera. A realidade fica mais dispersa. [...] o corte dentro da cena como o ato inaugural da arte cinematográfica"(LUCENA, 2009, p.116)

${ }^{13}$ Em uma versão em língua portuguesa da obra (MUSIL, 2003), leem-se muitas caracterizações do local em que a trama se desenrola, uma das primeiras é a seguinte: "Era uma pequena estação de trens, no caminho para Rússia"(p.7).

${ }^{14}$ Tradução nossa: A óbvia identificação de jovens de todo o mundo com seus pares.
} 
conduzir nossos pensamentos e reflexões em direção a outro mundo, o seu próprio mundo materializado em seus escritos. Mundo idealizado, utópico, poético.

A Etnomatemática de D’Ambrosio, em seus primeiros anos de criação, em seus primeiros momentos de divulgação, nas décadas de 1980 e 1990, é eminentemente parte de uma criação verbal - como, por exemplo, a criação etimológica etno + matem+ tica - e, esta criação, se apresenta como uma solução poética para os problemas enunciados em seu mundo próprio. A oralidade e, portanto, a retórica, marcam os discursos inscritos na narrativa das histórias que emergem da etnomatemática d'ambrosiana.

A composição da intriga em D’Ambrosio apresenta um homem genérico, herdeiro de um passado histórico clássico, grego, que cresce na modernidade e se converte em produto dos avanços tecnológicos que ele mesmo cria. O belo e o feio, a destruição e a construção do mundo, o bom e o mau, disputam espaço na trama desta história. O homem deve se implicar eticamente nesta história da História para se tornar o salvador do próprio homem (tradicional, obsoleto, destrutivo, etc.). Esse homem-tecnológico, dependente da matemática, pacífico, é também aquele que poderá salvar todo o planeta. A matemática e seu ensino são entendidos neste contexto como a base de todas as mudanças necessárias para promover o bem estar social global.

A trama tecida na narrativa do texto etnomatemáttico é, ainda, neste recorte, um reflexo do seu tempo, herdeira da modernidade científica e das ficções utópicas burguesas que povoam, direta ou indiretamente, o universo literário ficcional burguês.

Ao criar um mundo potencial, ao dirigir-se para um futuro provável, ao acionar o campo ficcional, torna-se possível para o escritor explorar o inexistente a partir do passado interpretado e enunciado em seu mundo do texto. Retrospectivamente, ao revisitar a obra textual etnomatemática de D’Ambrosio, ao localizar o espaço-tempo de sua produção, nota-se que ela fez exatamente isto.

O modo como o matemático narra suas histórias da História, elencando personagens reais e irreais, descrevendo cenários prováveis e pintando um presente e um passado em declínio, em mudança, em transição, contribuem para a construção de novas subjetividades no contexto das pesquisas em Educação Matemática. Novos olhares para antigos problemas - o ser do homem, as relações intersubjetivas, o homem em sociedade, os diferentes modos de aprender e ensinar, etc.

Seu trabalho, por fim, não se limitou a descrever o que estava diante dos olhos, mas, sim, ultrapassou os limites do factual e se lançou à fabulação de um provável mundo novo, inspirando e movendo a pesquisa. 
10. Referências

BAMPI, Lisete. Governo etnomatemático: tecnologias do multiculturalismo. 2003, 200f. Tese (Doutorado); Programa de Pós-Graduação em Educação, Faculdade de Educação, Universidade Federal do Rio Grande do Sul, Porto Alegre, 2003.

CARNEIRO, José Vanderlei. Hermenêutica da narratividade de ficção: a intriga como mediação do sentido. Pensando, revista de Filosofia. 4(8). p.72-102, 2013.

CIORAN, Émile Michel. História e Utopia. Tradução de José Thomaz Brum. Rio de Janeiro: Rocco, 1994.

BREDA, Adriana. A Utilização da Etnomatemática nos Cursos de Formação Continuada de Professores: um Ensaio Analítico sobre a Produção de Subjetividades. Dissertação (Mestrado) Programa de Pós-Graduação em Educação em Ciências e Matemática; Faculdade de Física, PUCRS. Porto Alegre, 2011.

CONRADO, Andréa Lunkes. A pesquisa brasileira em etnomatemática: desenvolvimento, perspectivas, desafios. 2005. Dissertação (Mestrado em Educação) Programa de Pós-graduacción em Educacción, Universidade de São Paulo.São Paulo: USP, 2005.

D’AMBROSIO, Ubiratan. Socio-Cultural bases for Mathematics education. Transcrição de uma palestra realizada pelo autor. São Paulo: UNICAMP, 1985.

D'AMBROSIO, Ubiratan. Da realidade à ação: reflexões sobre Educação e Matemática. São Paulo: Summus; Campinas: Ed. Da Universidade Estadual de Campinas, 1986.

D’AMBROSIO, Ubiratan. Etnomatemática: Arte ou técnica de explicar ou conhecer. São Paulo: Ática, 1990.

D’AMBROSIO, Ubiratan. Educação para una sociedade em transição. Campinas: Papirus, 1999.

D’AMBROSIO, Ubiratan. Etnomatemática: Elo Entre as Tradições e a Modernidade. Coleção tendências em Educação Matemática, 4. Belo Horizonte: Autêntica, 2011.

FALCON, Francisco José Calazans. Utopia e Modernidade. Morus: Utopia e Renascimento. Campinas: Unicamp, 2005, n. 2, p. 161-184.

FANTINATO, Maria Cecília; FREITAS, Adriano Vargas (Orgs.). Etnomatemática: concepções, dinâmicas e desafios. Jundiaí: Paco, 2018. 232p.

FIRPO, Luigi. Para uma Definição de "Utopia". Morus: Utopia e Renascimento. Campinas: Unicamp, 2005, n. 2, p. 225-237.

GERDES, Paulus. Etnomatemática e Educação Matemática: Um panorama geral. Revista Quadrante: Lisboa, 5(2), 105-138, 1996.

GERDES, Paulus. Da etnomatemática a arte-design e matrizes cíclicas. Coleção tendências em Educação Matemática. Belo Horizonte: Autêntica, 2010. 
KERMODE, Frank. The sense of an ending: studies in the theory of fiction. New York: Oxford University Press, 2000.

KNIJNIK, Gelsa (et Al.). Etnomatemática em movimento. Coleção tendências em educação matemática, 25. Belo horizonte: Editora autêntica, 2012.

KNIJNIK, Gelsa. Itinerários da etnomatemática: questões e desafios sobre o cultural, o social e o político na educação matemática. In: KNIJNIK, Gelsa.; WANDERER, Fernanda; OLIVEIRA, Claudio José. (Org.). Etnomatemática, currículo e formação de professores. Santa Cruz do Sul: EDUNISC, 2004. p. 19-38.

LUCENA, Luiz Carlos. Nem tudo é verdade (not everything is true) A construção do Real no Documentário Contemporâneo. Ensaio base para dissertação de mestrado (2007). São Paulo: USP, 2009.

MARCHON, Fabio Lennon. A Poética, a Retórica e a Narrativa do Mundo do Texto etnomatemático d'ambrosiano. Tese (doutorado). Universidade Federal Fluminense. Faculdade de Educação. 2018. 266 p.

MARQUES, Paulo Sérgio. A poética do perfeito: elementos da narrativa utópica. Revista FronteiraZ. PUC-SP, 2009. p1-13. Disponível em https://revistas.pucsp.br/fronteiraz/article/view/12464/9035 (visualizado em 14/08/2020)

MENEGHETTI, Francis Kanashiro. O que é um ensaio-teórico?. Rev. adm. contemp., Curitiba , v. 15, n. 2, p. 320-332, Abril 2011 . Disponível em $<$ http://www.scielo.br/scielo.php?script=sci_arttext\&pid=S 141565552011000200010\&lng=en\&nrm=iso>. Acesso em 03 de Julho de 2020.

MIARKA, Roger. Etnomatemática: do ôntico ao ontológico. Tese (doutorado). Universidade Estadual Paulista Júlio de Mesquita Filho, Rio Claro, 2011.

MOISES, Massaud. A criação literária: poesia e prosa. São Paulo: Cultrix, 2012. 317p.

MUSIL, Robert. O Jovem Törless. Coleção Biblioteca Folha, 27. São Paulo: Ed. Folha de São Paulo. 2003. 157p.

REUTER, Yves. A análise da narrativa: o texto, a ficção e a narração. Rio de Janeiro: Difel, 2014.

RICOEUR, Paul. Interpretação e ideologias. Tradução Hilton Japiassu. Rio de Janeiro: Francisco Alves, 1990.

RICOEUR, Paul. A Memória, a história, o esquecimento. Tradução Alain François [et al.]. Campinas, SP: Editora da Unicamp, 2007.

RICOEUR, Paul. Teoria da interpretação: o discurso e o excesso de significação. Lisboa: Edições 70, 2011.

RICOEUR, Paul. Entre tempo e narrativa: concordância/discordância. Kriterion, Belo Horizonte , v. 53, n. 125, p. 299-310, June 2012. Disponível em 
<http://www.scielo.br/scielo.php?script=sci_arttext\&pid=S0100-

512X2012000100015\&lng=en\&nrm=iso>. Acesso em 03 de Julho de 2020.

RICOEUR, Paul. Tempo e narrativa 1: A intriga e a narrativa histórica. São Paulo: Martins Fontes, 2012a.

RICOEUR, Paul. Tempo e narrativa 2: A configuração do tempo na narrativa de ficção. São Paulo: Martins Fontes, 2012b.

RICOEUR, Paul.Tempo e narrativa 3: O tempo narrado. São Paulo: Martins Fontes, 2012c. RICOEUR, Paul. O Discurso da Ação. Lisboa: Edições 70, 2013.

RICOEUR, Paul. A Metáfora Viva. Tradução Dion Davi Macedo. Coleção Leituras Filosóficas. São Paulo: Edições Loyola, 2015.

ROSA, Milton; OREY, Daniel Clark. Fragmentos Históricos do Programa Etnomatemática. In Anais/Acta do 6o. Encontro Luso-Brasileiro de História da Matemática, 2014.p.335-358.

SARGENT, Lyman Tower. What Is a Utopia? Morus: Utopia e Renascimento. Campinas: Unicamp, 2005, n. 2, p. 153-160.

TROUSSON, Raymond. Utopia e Utopismo. Morus: Utopia e Renascimento. Campinas: Unicamp, 2005, n. 2, p. 123-135.

WHITE, Hayden. Trópicos do Discurso: Ensaios sobre a crítica da cultura. São Paulo: Editora da Universidade de São Paulo, 2014; 